\title{
Características Agronômicas e Composição Química de Oito Híbridos de Sorgo [Sorghum bicolor (L.) Moench $]^{1}$
}

\author{
Márcio dos Santos Pedreira ${ }^{2}$, Ricardo Andrade Reis ${ }^{3}$, Telma Teresinha Berchielli ${ }^{3}$, Andréia \\ Luciane Moreira ${ }^{4}$, Rogério Marchiori Coan ${ }^{5}$
}

\begin{abstract}
RESUMO - O experimento foi conduzido com o objetivo de avaliar as características agronômicas, composição química das frações e da planta inteira de oito híbridos de sorgo, semeados em março de 2000, no sentido de contribuir para os programas de seleção de germoplamas resistentes aos efeitos das estiagens prolongadas e, ao mesmo tempo, apropriados ao processo de ensilagem. Utilizou-se o delineamento em blocos ao acaso com oito tratamentos e três repetições, para avaliar os híbridos AG-2005, BR-700, MASSA-03, 498111, 65E3, 698005, 698007 e 699005. Não houve diferenças significativas entre produção de matéria seca (PMS) e proporção de folhas dos híbridos avaliados. A maior proporção de colmo (41,3\%) foi observada no 498111 e a menor no MASSA-03 (28,9\%). O híbrido 65E3 apresentou a maior proporção de panícula (43,2\%) e o 498111 a menor (28,9\%). Quanto à composição química da planta inteira, não foram observadas diferenças significativas entre os híbridos quanto aos teores de matéria seca, matéria mineral, hemicelulose, nitrogênio insolúvel em detergente neutro, nitrogênio insolúvel em detergente ácido e nutrientes digestíveis totais (NDT). Os teores de proteína bruta variaram de 6,5 a 8,8\%, fibra em detergente neutro de 57,0 a 70,3\%, fibra em detergente ácido de 29,8 a $36,2 \%$, celulose de 25,3 a $31,2 \%$ e lignina de 3,6 a 5,5\%, sendo estatisticamente diferentes entre os híbridos. O 699005 apresentou o maior teor de carboidratos solúveis (14,5\%), diferindo estatisticamente apenas do híbrido 698007 (9,6\%). Os híbridos também mostraram diferenças na composição química das frações folhas, colmo e panícula. De forma geral, todos os híbridos apresentaram teores de matéria seca e carboidratos solúveis adequados ao processo de ensilagem. As produções médias de matéria seca dos híbridos (6,2 t/ha), foram altas considerando-se a baixa precipitação ocorrida durante o período experimental. A análise de Cluster sugeriu o agrupamento dos híbridos de maior PMS e menores porcentagens de panícula e NDT e híbridos de menor PMS, porém com maiores porcentagens de panícula e NDT.
\end{abstract}

Palavras-chave: carboidratos solúveis, produção, composição morfológica

\section{Agronomic Characteristics and Chemical Composition of Eight Sorghum Hybrids [Sorghum bicolor (L.) Moench]}

\begin{abstract}
This research was developed to evaluate the agronomic characteristics, chemical composition of the whole plants and their fractions of eight sorghum hybrids, to identify the adapted plants to dry environmental conditions and appropriated to silage production. The experiment was conducted according to a randomized block design, with eight treatments and three replications, to study the commercial hybrids AG-2005, BR-700 and MASSA-03, and the non commercial hybrids 498111, 65E3, 698005, 698007 and 699005. There were no significant differences among hybrids in relation to the plant height, dry matter production and leaf proportion, it was observed highest stem content (43.3\%) in the 498111 hybrid and lowest in the MASSA-03 (29.9\%). The 65E3 showed highest panicle contents (43.2\%), however the lowest value was observed in the 498111 hybrid (28.9\%). The contents of dry matter, ashes, hemicellulose, neutral detergent insoluble nitrogen, acid detergent insoluble nitrogen and total digestible nutrients of the whole plant were similar among hybrids. It was observed different values of crude protein ( 6.5 to $8.8 \%$ ), neutral detergent fiber ( 57.0 to $70.3 \%$ ), acid detergent fiber ( 29.8 to $36.2 \%$ ), cellulose (25.3 to $31.2 \%$ ) and lignin (3.6 to 5.5\%) of the hybrids. The content of soluble carbohydrates of hybrid 699005 $(14.5 \%)$ was higher than the 698007 (9.6\%). The hybrids showed differences on chemical composition of the leaf, stem, and panicle fractions. The dry matter and soluble carbohydrates contents of all hybrids were appropriate to the ensilage process. The average dry matter yield of all hybrids was $6.2 \mathrm{t} / \mathrm{ha}$. This value was high considering the low rainfall during the experimental period. The Cluster analyses suggest a group of the sorghum hybrids with higher dry matter production (DMP), lower panicle percentage, and TDN content, and others with lower DMP, but higher panicle percentage, and TDN values.
\end{abstract}

Key Words: morphological composition, water soluble carbohydrates, yield

\footnotetext{
1 Parte da Dissertação de Mestrado do primeiro autor, projeto financiado pela Dow Agroscience.

2 Professor DTRA/UESB, Itapetinga, BA. Pós-graduando da FCAV/UNESP, Bolsista CAPES, Jaboticabal, SP. E.mail: pedreira@fcav.unesp.br

3 Professor da FCAV/UNESP, Jaboticabal, SP. Pesquisadores CNPq. E.mail: ttberchi@fcav.unesp.br; rareis@fcav.unesp.br

4 Pós-graduando da FCAV/UNESP, Jaboticabal, SP. Bolsista FAPESP. E.mail: aluciane@fcav.unesp.br

${ }^{5}$ Pós-graduando de FCAV/UNESP, Jaboticabal, SP. Bolsista CNPq. E.mail: rogeriocoan@netsite.com.br
} 


\section{Introdução}

A baixa precipitação e sua distribuição irregular estão entre as principais causas que afetam a produtividade das forrageiras nas atividades agropecuárias no Brasil. Assim, tornam-se necessários estudos que permitam a exploração de plantas cujas exigências possam ser atendidas com baixa disponibilidade hídrica.

Atualmente, o sorgo tem se destacado como espécie que tem resistência a fatores ambientais adversos, elevadas produções de massa seca por área, bom padrão de fermentação e elevado valor nutritivo das silagens produzidas. Por esses motivos, tem havido no Brasil aumento das áreas cultivadas com esta cultura, correspondendo a aproximadamente 10 a $12 \%$ da área total cultivada para silagem (Zago, 1991). Segundo Zago (1999), em 1991/1992 foram plantados no Brasil em torno de 55.000 ha de sorgo destinados à ensilagem.

A variabilidade genética desta espécie permitiu o desenvolvimento de trabalhos de melhoramento que proporcionaram a obtenção de um grande número de híbridos. Cada um destes materiais apresenta características agronômicas e valor nutritivo diferentes, com conseqüentes variações quanto à produtividade e padrões de fermentação, resultando em silagens com diferentes qualidades. Esses fatores podem afetar diretamente o desempenho dos animais consumindo esse alimento, tornando evidente a necessidade de estudos que conduzam a seleção de híbridos mais adequados aos sistemas de produção animal.

Diversos trabalhos mostraram larga amplitude na produtividade do sorgo, variando em função da época de semeadura, das condições ambientais durante o período de cultivo e do grande número de variedades existentes (Pereira, 1991; Demarchi et al., 1995; Valente, 1997). Em sistemas de sucessão de culturas, o sorgo pode ser plantado após as colheitas das culturas de verão, o que normalmente ocorre em fevereiro e início de março. Esta alternativa tem sido cada vez mais utilizada, principalmente devido às características do sorgo quanto à tolerância à escassez de chuvas, o que deve favorecer melhor uso do solo, garantindo melhores resultados econômicos à atividade.

Silagens de sorgo proveniente de cultivares forrageiros produzem maior quantidade de biomassa por área, porém geram resultados inferiores quanto ao desempenho animal, comparado aos obtidos com silagem de milho (Nussio, 1993). Por outro lado, Owen (1967) não reportou diferenças quanto ao ganho de peso de novilhos alimentados com sorgo de baixa e alta relação de grãos/colmo ou sorgo de duplo propósito.

Ao avaliarem a estrutura morfológica de híbridos de sorgo, Gourley \& Lusk (1977) encontraram plantas com proporções de colmo variando de 17,1 a $72,8 \%$ na MS; folhas variando de 17,4 a $26,3 \%$; e panículas de 5,2 a 64,6\%. Segundo Silva et al. (1999), a variação nas proporções da planta deve-se à grande variabilidade genética dos materiais utilizados, o que pode interferir diretamente na qualidade da planta e conseqüentemente da silagem produzida.

Segundo Van Soest (1994), na forragem em estádio de pós-florescimento, os colmos são freqüentemente de menor qualidade e a relação folha-colmo pode ser usada como um indicativo do valor nutritivo da planta. Entretanto, em alguns casos, devido à existência de variações entre cultivares, esta relação deve ser usada com cautela, pois nos materiais que apresentam a mesma digestibilidade entre estas partes, a relação pode não ser válida. Para Minson (1990), os colmos das gramíneas imaturas são geralmente de alta qualidade e até mesmo de qualidade mais alta que as folhas. Entretanto, a qualidade do colmo decresce mais rapidamente do que a das folhas, especialmente com a aproximação da maturidade da planta (Nelson \& Moser, 1994).

Para reduzir perdas de qualidade da planta, temse selecionado cultivares que apresentem a característica "stay green", ou seja, o colmo se mantém verde por tempo mais prolongado. Quando se melhora a qualidade do colmo, principalmente pela redução dos constituintes da parede celular e aumento dos açúcares solúveis, aumenta-se a freqüência de acamamento das plantas, principalmente em cultivares de porte alto com proporção elevada de panícula.

Este trabalho foi realizado com o objetivo de avaliar as características agronômicas de oito híbridos de sorgo (Sorghum bicolor (L.) Moench), cultivados no período de entressafra, no sentido de contribuir para os programas de seleção de germoplamas resistentes aos efeitos das estiagens prolongadas e ao mesmo tempo apropriados ao processo de ensilagem de alta qualidade.

\section{Material e Métodos}

O experimento foi desenvolvido no Departamento de Zootecnia da Faculdade de Ciências Agrárias e Veterinárias/UNESP, campus de Jaboticabal. 
O solo da área experimental foi classificado como Latossolo vermelho, (HAPLUSTOX). Os índices pluviométricos registrados durante o período de cultivo encontram-se na Tabela 1.

O experimento foi implantado em março de 2000, considerado como cultura de "safrinha", em um delineamento experimental de blocos ao acaso com oito tratamentos e três repetições, utilizando-se os híbridos de sorgo: BR-700, MASSA-03, AG-2005, 699005, 698007, 698005, 498111 e 65E3.

$\mathrm{Na}$ adubação de semeadura, foram utilizados 300 $\mathrm{kg} / \mathrm{ha}$ da fórmula 04-28-20. Também foi efetuada adubação nitrogenada de cobertura 30 dias após a emergência das plantas, com $60 \mathrm{~kg}$ de N/ha, na forma de nitrato de amônio.

A semeadura foi feita manualmente no dia 22 de março de 2000, procurando-se obter uma densidade de 180.000 plantas por hectare. As parcelas experimentais foram constituídas por oito linhas de 5 metros de comprimento cada, com espaçamento de $0,7 \mathrm{~m}$ entre linhas. Foi considerada área útil da parcela, as quatro linhas internas, excluindo-se $1 \mathrm{~m}$ em cada extremidade.

O corte para ensilagem foi feito quando os grãos de cada híbrido estudado atingissem o ponto farináceo, o que representou 99 dias para o AG-2005 e o BR-700, 107 dias para o MASSA-03, 65E3 e o 699005 e 113 dias para os híbridos 498111, 698005 e 698007.

Foram determinadas a produção de matéria seca e a proporção de colmo, folhas e panícula nas plantas. $\mathrm{Na}$ fração folha incluiu-se a lâmina e a bainha, e a panícula foi separada na inserção da última folha. Da área útil de cada parcela, foram colhidas as plantas de uma linha para separação em suas partes componentes. As frações foram secas em estufa a $65^{\circ} \mathrm{C}$, com

Tabela 1 - Precipitação $(\mathrm{mm})$ mensal durante o período experimental

Table 1 - Monthly rainfall $(\mathrm{mm})$ during the experimental period

\begin{tabular}{lccccc}
\hline Total & \multicolumn{5}{c}{$\begin{array}{c}\text { Mês } \\
\text { Total }\end{array}$} \\
\cline { 2 - 6 } & $\begin{array}{c}\text { Março } \\
\text { March }\end{array}$ & $\begin{array}{c}\text { Abril } \\
\text { April }\end{array}$ & $\begin{array}{c}\text { Maio } \\
\text { May }\end{array}$ & $\begin{array}{c}\text { Junho } \\
\text { June }\end{array}$ & $\begin{array}{c}\text { Julho } \\
\text { July }\end{array}$ \\
\hline $\begin{array}{l}\text { Mensal } \\
\text { Monthly }\end{array}$ & 57,5 & 51,2 & 3,0 & 1,5 & 0,0 \\
$\begin{array}{l}\text { Total } \\
\text { Total }\end{array}$ & & & & & 113,2 \\
\hline
\end{tabular}

Fonte: Estação Agroclimatológica/Dep. de Ciências Exatas/FCAV/ UNESP (2000)

R. Bras. Zootec., v.32, n.5, p.1083-1092, 2003 circulação forçada de ar, por 72 horas, e posteriormente desintegradas em moinho tipo "Wiley" com peneira de malha de $1 \mathrm{~mm}$ (Silva, 1998), para análises laboratoriais.

$\mathrm{O}$ restante da área útil da parcela foi colhido, pesado e picado em pedaços de tamanho aproximado de $2 \mathrm{~cm}$, em máquina forrageira tipo desintegradora, picadora e moedora (DPM). Foram retiradas amostras, que foram pré-secas e analisadas, seguindo a mesma metodologia adotada para os constituintes da planta.

Nas amostras pré-secas das partes e da planta inteira foram determinados: concentração de matéria seca (MS) em estufa a $105^{\circ} \mathrm{C}$ (Silva, 1998); teores de proteína bruta (PB) pelo método de combustão de Dumas (Etheridge et al., 1998) utilizando-se um analisador automático de proteína da marca Leco 528LC; e fibra em detergente neutro (FDN), fibra em detergente ácido (FDA) e lignina, pelo método seqüencial descrito por Van Soest et al. (1991), utilizando-se a técnica Filter Bag - FTB (ANKOMâ). Antes da análise dos componentes da parede celular, foram adicionados dois $\mathrm{mL}$ de uma solução de amilase a $1 \%$ em cada amostra. Para a determinação da lignina foi utilizado o ácido sulfúrico a 72\% (Van Soest, 1994). Os teores de hemicelulose foram calculados por diferença entre os valores de FDN e FDA, e a celulose por diferença entre os de FDA e lignina. Nos resíduos da FDN e da FDA, foram realizadas as análises de nitrogênio insolúvel em detergente neutro (NIDN) e de nitrogênio insolúvel em detergente ácido (NIDA), pela mesma metodologia descrita para a determinação do nitrogênio total. A determinação dos teores de carboidratos solúveis foi realizada na amostra pré-seca da planta inteira antes da ensilagem, pela metodologia descrita por Johnson et al. (1966), com leitura em espectrofotômetro em comprimento de onda de 480 $\mathrm{nm}$. Também foram estimados os valores de nutrientes digestíveis totais (NDT), utilizando-se as equações propostas pelo NRC (2001):

Os resultados foram avaliados pela análise de variância e comparação de médias pelo teste Tukey $(\mathrm{P}<0,05)$, por meio de programa ANOVA (SAS, 1990). A partir das médias obtidas foi realizada análise de agrupamento utilizando o procedimento Cluster (Bussab et al., 1990) para verificação da similaridade entre os híbridos de sorgo avaliados, considerados objetivos, e a produção de matéria seca (PMS), porcentagem de panícula na planta (PAN), 
NDT e PB como variáveis de interesse para critérios de parecença (similaridade), que foram determinados pelo método das distâncias médias (MMD).

\section{Resultados e Discussão}

\section{Características agronômicas}

Não foram encontradas diferenças entre híbridos para produção de matéria seca e proporção de folhas, enquanto as proporções de colmo e de panícula variaram entre híbridos (Tabela 2). O híbridos 698007 apresentou uma das maiores proporções de colmos $(38,3 \%)$ e pequena participação de panículas nas plantas $(32,9 \%)$.

A produção de matéria seca por hectare foi inferior àquelas obtidas por Flaresso et al. (2000) que avaliando híbridos de sorgo, em cultivos de novembro, obtiveram, em média, rendimento de 15 t/ha de matéria seca, o que já era esperado. Além disso, o período de cultivo foi marcado por estresse hídrico acentuado (Tabela 1), o que proporcionou baixa produção de matéria seca dos híbridos.

Segundo Pimentel et al. (1977), para obtenção de máxima produção das culturas de sorgo forrageiro, semeados em outubro e novembro, as precipitações mínimas durante período do cultivo devem ser de 240 $\mathrm{mm}$, bem distribuídos entre os três primeiro meses após a semeadura; precipitações inferiores poderiam representar, em média, perdas de produção de até $20 \%$, porem os autores não relataram exigências para os cultivos de março.

No presente estudo, a precipitação total durante o ciclo de cultivo foi de $113 \mathrm{~mm}, 47 \%$ inferior ao recomendado por Pimentel et al. (1977), com maior ocorrência de chuvas no primeiro mês após a semeadura.

A produção de matéria seca observada no estudo (Tabela 2) representou, em média, $60 \%$ da produção de cultivos de novembro e dezembro (Neumann et al., 2002a; Flaresso et al., 2000).

Henrique \& Andrade (1997) avaliaram um híbrido de sorgo (C-51), semeado em 28 de março, e obtiveram produção de massa seca de 8,6 t/ha, $28 \%$ superior à média de produção aqui obtida, entretanto, registraram ocorrência de $215 \mathrm{~mm}$ de precipitação durante o período experimental, $48 \%$ superior ao observado no presente estudo.

Observou-se menor participação da fração colmo no híbrido MASSA-03 (28,9\%), que, entretanto, diferiu $(\mathrm{P}<0,05)$ apenas do híbrido $498111(41,3 \%)$.
A maior participação dessa fração nas plantas foi nos híbridos 498111 e 698007 com porcentagens de 41,3 e $38,3 \%$, respectivamente. Estas variações também foram encontradas por outros autores, que obtiveram participações do colmo de 20 a $54 \%$ em híbridos de duplo propósito (Neumann et al., 2002ab; Flaresso et al., 2000). Na fração folhas, houve pequenas variações entre os materiais analisados, de 26,7 até $34,4 \%$ para os híbridos 65E3 e 699005, respectivamente, sem diferirem estatisticamente.

As maiores proporções de panícula na planta foram nos híbridos 65E3, BR-700 e AG-2005 com 43,$2 ; 42,2$ e $41,1 \%$, respectivamente. Entretanto houve diferença $(\mathrm{P}<0,05)$ apenas para os híbridos $65 \mathrm{E} 3$ e BR-700 em relação ao híbrido 498111, que apresentou a menor proporção de panícula $(28,9 \%)$.

Trabalhos realizados por Flaresso et al. (2000) demonstraram variações de porcentagem de panícula na planta inteira de 33 a $51 \%$. Esses autores observaram participação de panícula na planta de $47,4 \mathrm{e}$ 43,9\%, respectivamente para os híbridos AG-2005 e BR-700, e esses valores foram próximos aos obtidos neste trabalho.

\section{Características químicas}

Os teores de MS variaram de 34,4 a 39,1\%, sem diferirem entre si, estando de acordo com Zago (1999) que indicou teores de matéria seca nas plantas

Tabela 2 - Características agronômicas dos híbridos de sorgo no estádio de grão farináceo

Table 2 - Agronomic characteristics of sorghum hybrids in the hard-dough grain stage

\begin{tabular}{lcccc}
\hline $\begin{array}{l}\text { Híbridos } \\
\text { Hybrids }\end{array}$ & PMS $^{1}$ & \multicolumn{3}{c}{ Componentes (\% na MS) } \\
& DMP $^{1}(t / h a)$ & \multicolumn{3}{c}{ Components (\% of $D M)$} \\
\cline { 3 - 5 } & & $\begin{array}{c}\text { Colmo } \\
\text { Steam }\end{array}$ & $\begin{array}{c}\text { Folhas } \\
\text { Leaves }\end{array}$ & $\begin{array}{c}\text { Panícula } \\
\text { Panicle }\end{array}$ \\
\hline 498111 & 6,9 & $41,3^{\mathrm{a}}$ & 29,6 & $28,9^{\mathrm{b}}$ \\
$65 \mathrm{E} 3$ & 5,6 & $30,1^{\mathrm{ab}}$ & 26,7 & $43,2^{\mathrm{a}}$ \\
698005 & 6,4 & $35,6^{\mathrm{ab}}$ & 33,4 & $30,9^{\mathrm{ab}}$ \\
698007 & 7,1 & $38,3^{\mathrm{ab}}$ & 28,7 & $32,9^{\mathrm{ab}}$ \\
699005 & 6,2 & $33,2^{\mathrm{ab}}$ & 34,4 & $32,4^{\mathrm{ab}}$ \\
AG-2005 & 5,8 & $29,9^{\mathrm{ab}}$ & 29,5 & $41,1^{\mathrm{ab}}$ \\
BR-700 & 5,1 & $29,9^{\mathrm{ab}}$ & 27,8 & $42,2^{\mathrm{a}}$ \\
MASSA-03 & 6,3 & $28,9^{\mathrm{b}}$ & 32,5 & $38,5^{\mathrm{ab}}$ \\
DMS $^{2}$ & 3,2 & 12,0 & 13,2 & 12,3 \\
MSD $^{2}$ & & & &
\end{tabular}

Médias seguidas por letras diferentes na coluna diferem $(P<0,05)$ pelo teste Tukey.

1 Produção de matéria seca.

2 Diferenças mínimas significativas.

Means followed by different letters, within a column, differ $(P<.05)$ by

Tukey test.

1 Dry matter yield.

2 Minimum significant differences. 
submetidas à ensilagem entre 30 e $40 \%$ para obtenção de silagens de sorgo com alto valor nutritivo. Estas variações decorreram principalmente dos conteúdos de MS na panícula, bem como sua proporção nas plantas e também as diferentes idades de corte dos materiais, necessário para colher os híbridos no mesmo estádio de maturação. Outro fato que proporcionou esses teores de MS nas plantas foi o estresse hídrico, que acelerou a senescência e incremento de MS das folhas, que variaram de 37,4 a 47,6\%, acima dos valores freqüentemente observados por outros autores, entre 25 a 35\% (Neumann et al., 2002ab; Neumann et al., 2002b).

A concentração de proteína bruta na matéria seca dos materiais analisados esteve acima do mínimo desejado para garantir fermentação ruminal adequada, que, segundo Van Soest (1994), é de 6\%. O menor teor de proteína foi encontrado no híbrido 498111 (6,5\%) que diferiu apenas do BR-700 (8,8\%).

A menor porcentagem de panícula nas plantas do híbrido 498111 determinou menores concentrações de proteína bruta na planta inteira, marcando a importância deste constituinte para a qualidade da planta.

Os teores de matéria mineral variaram de 2,8\% no híbrido 65E34 a 4,0\% no híbrido 698007. Para esta variável não houve diferenças entre os genótipos.

Os teores de carboidratos solúveis variaram de $9,6 \%$ no 698007 até $14,5 \%$ no 699005 , acima do valor mínimo necessário para garantir fermentação lática das silagens, que de acordo McDonald et al. (1991) deve ser de 6 a $8 \%$. Por outro lado, Johnson et al. (1971) consideraram teores de $15 \%$ como mínimo para garantir fermentação lática durante a armazenagem de plantas forrageiras cortadas precocemente. Pesce et al. (2000) encontraram valores de carboidratos solúveis variando de 3,7 a 12,0\% em híbridos de sorgo.

As diferentes proporções de panícula e de carboidratos solúveis nas plantas não foram suficientes para inferir diferenças nos valores estimados de NDT, que não diferiram entre os híbridos, $(63,1$ a $68,4 \%)$ estando acima dos valores médios $(55,3 \%)$ encontrados por Flaresso et al. (2000) e dentro dos teores (65 a 70\%) recomendados para obtenção de silagens de boa qualidade (Keplin, 1992). O método utilizado por estes autores (Ministry of Agriculture, Fisheries and Food) para cálculo do NDT pode ser uma das causas dessas diferenças.

O menor valor de FDN foi no híbridos AG-2005 (Tabela 3). Mas, Houve diferenças apenas entre o AG-2005 (57,0\%) e o 698007 (70,3\%), que apresentou o maior valor para esta variável. A variação dos teores de FDN entre híbridos de sorgo também foi observada por Pesce et al. (2000), os quais apresentaram resultados de FDN de 20 cultivares de sorgo variando de 57,4 a $66,5 \%$.

A relação entre alta proporção de colmo (Tabela 2) e alta porcentagem de parede celular na

Tabela 3 - Composição bromatológica e constituintes da parede celular da planta inteira de híbridos de sorgo Table 3 - Bromatologic composition and cell wall constituents of the whole plant of sorghum hybrids

\begin{tabular}{|c|c|c|c|c|c|c|c|c|c|c|c|c|}
\hline $\begin{array}{l}\text { Híbridos } \\
\text { Hybrids }\end{array}$ & $\begin{array}{l}\mathrm{MS}^{1} \\
D M^{1}\end{array}$ & $\begin{array}{l}\mathrm{PB}^{2} \\
C P^{2}\end{array}$ & $\begin{array}{l}\mathrm{MM}^{3} \\
\text { Ashes }\end{array}$ & $\begin{array}{l}\text { CHO's } \\
{ }^{4} \mathrm{WSC}^{3}\end{array}$ & $\begin{array}{l}\mathrm{NDT}^{5} \\
T D N^{4}\end{array}$ & $\begin{array}{l}\mathrm{FDN}^{6} \\
N D F^{5}\end{array}$ & $\begin{array}{l}\mathrm{FDA}^{7} \\
A D F^{6}\end{array}$ & $\begin{array}{l}\mathrm{Cel}^{8} \\
\mathrm{Cel}^{7} \\
\end{array}$ & $\begin{array}{l}\mathrm{Hem}^{9} \\
\mathrm{Hem}^{8}\end{array}$ & $\begin{array}{l}\operatorname{Lig}^{10} \\
\operatorname{Lig}^{9}\end{array}$ & $\begin{array}{c}\text { NFDN/NT } 11 \\
N D I N / T N^{10}\end{array}$ & $\begin{array}{c}\mathrm{NFDA} / \mathrm{NT}^{12} \\
A D I N / T N^{11}\end{array}$ \\
\hline 498111 & 35,2 & $6,5^{b}$ & 3,3 & $13,6^{\mathrm{ab}}$ & 67,5 & $57,4^{\mathrm{ab}}$ & $29,8^{b}$ & $25,3^{b}$ & 27,6 & $4,4^{\mathrm{abc}}$ & 32,4 & 16,1 \\
\hline $65 \mathrm{E} 3$ & 39,1 & $6,9^{b}$ & 2,8 & $12,3^{\mathrm{ab}}$ & 68,2 & $61,6^{\mathrm{ab}}$ & $32,7^{\mathrm{ab}}$ & $27,2^{\mathrm{ab}}$ & 28,8 & $5,5^{\mathrm{a}}$ & 40,3 & 16,4 \\
\hline 698005 & 36,9 & $6,8^{\mathrm{b}}$ & 3,4 & $10,9^{\mathrm{ab}}$ & 66,5 & $63,5^{\mathrm{ab}}$ & $36,2^{\mathrm{a}}$ & $31,2^{\mathrm{a}}$ & 27,3 & $4,9^{\mathrm{ab}}$ & 36,2 & 14,1 \\
\hline 698007 & 36,9 & $7,1^{b}$ & 4,0 & $9,6^{\mathrm{b}}$ & 64,1 & $70,3^{\mathrm{a}}$ & $36,0^{\mathrm{a}}$ & $31,1^{\mathrm{a}}$ & 34,3 & $4,9^{\mathrm{ab}}$ & 39,6 & 15,5 \\
\hline 699005 & 35,2 & $7,0^{\mathrm{b}}$ & 3,4 & $14,5^{\mathrm{a}}$ & 67,6 & $60,1^{\mathrm{ab}}$ & $34,0^{\mathrm{ab}}$ & $30,3^{\mathrm{ab}}$ & 26,1 & $3,6^{\mathrm{c}}$ & 32,4 & 12,4 \\
\hline AG-2005 & 34,4 & $7,7^{\mathrm{ab}}$ & 3,5 & $10,5^{\mathrm{ab}}$ & 68,4 & $57,0^{\mathrm{b}}$ & $32,2^{\mathrm{ab}}$ & $28,0^{\mathrm{ab}}$ & 24,8 & $4,2^{b c}$ & 34,2 & 16,3 \\
\hline BR-700 & 35,7 & $8,8^{\mathrm{a}}$ & 3,6 & $12,5^{\mathrm{ab}}$ & 63,1 & $59,1^{\mathrm{ab}}$ & $33,0^{\mathrm{ab}}$ & $28,4^{\mathrm{ab}}$ & 26,1 & $4,6^{\mathrm{abc}}$ & 29,4 & 19,5 \\
\hline MASSA-03 & 37,4 & $7,3^{\mathrm{b}}$ & 3,3 & $11,1^{\mathrm{ab}}$ & 66,7 & $57,6^{\mathrm{ab}}$ & $32,1^{\mathrm{ab}}$ & $28,0^{\mathrm{ab}}$ & 25,5 & $4,1^{b c}$ & 25,1 & 13,6 \\
\hline $\mathrm{CV}^{13}(\%)$ & 6,1 & 6,9 & 11,7 & 12,0 & 4,1 & 7,3 & 5,9 & 6,7 & 12,9 & 9,1 & 22,6 & 18,7 \\
\hline$C V^{12}(\%)$ & & & & & & & & & & & & \\
\hline $\begin{array}{l}\mathrm{DMS}^{14} \\
M S D^{13}\end{array}$ & 6,4 & 1,4 & 1,1 & 4,1 & 7,8 & 12,9 & 5,6 & 5,6 & 10,3 & 1,1 & 22,0 & 8,4 \\
\hline
\end{tabular}

Médias seguidas por letras diferentes na coluna diferem $(P<0,05)$ pelo teste Tukey.

${ }^{1}$ Matéria seca, 2 proteína bruta, ${ }^{3}$ matéria mineral, ${ }^{4}$ carboidratos solúveis, ${ }^{5}$ nutrientes digestíveis totais, ${ }^{6} \mathrm{fibra}$ em detergente neutro, ${ }^{7}$ fibra em detergente ácido, ${ }^{8}$ celulose, 9 hemicelulose, ${ }^{10}$ lignina, ${ }^{11}$ nitrogênio insolúvel em detergente neutro em relação ao nitrogênio total, ${ }^{12}$ nitrogênio insolúvel em detergente ácido em relação ao nitrogênio total, ${ }^{13}$ coeficientes de variação, ${ }^{14}$ diferenças mínimas significativas.

${ }^{1}$ Dry matter, ${ }^{2}$ crude protein, ${ }^{3}$ water soluble carbohydrates, ${ }^{4}$ total digestible nutrients, ${ }^{5}$ neutral detergent fiber, ${ }^{6}$ acid detergent fiber, ${ }^{7}$ cellulose, ${ }^{8}$ hemicellulose, ${ }^{9}$ Lignina, ${ }^{10}$ neutral detergent insoluble nitrogen by total nitrogen, ${ }^{11}$ acid detergent insoluble nitrogen by total nitrogen, ${ }^{12}$ coefficients of variation, ${ }^{13}$ minimun significant differences.

Means followed by different letters, within a column, differ $(P<.05)$ by Tukey test.

R. Bras. Zootec., v.32, n.5, p.1083-1092, 2003 
constituição química da planta inteira não foi mantida no híbrido 498111, que pode ser explicado pela melhor composição química do colmo nessas plantas, favorecendo a composição final da forragem. Assim, a composição química das plantas deve ser entendida como o resultado da proporção de colmo, folhas e panícula e da composição química dessas frações.

O teor de FDA foi menor no 498111, diferindo $(\mathrm{P}<0,05)$ de 698005 e 698007 , que apresentaram os maiores teores deste constituinte químico. Este mesmo comportamento foi observado para os teores de celulose nas plantas avaliadas, onde o híbrido 498111 também apresentou a menor porcentagem de celulose, diferindo $(\mathrm{P}<0,05)$ dos híbridos 698005 e 698007. Estes resultados estiveram próximos aos obtidos por Chaves (1997), que, avaliando híbridos de sorgo forrageiro, encontrou teores de FDA na planta variando de 30,1 a $35,4 \%$. Não foram observadas diferenças entre os híbridos para a variável hemicelulose.

A maior concentração de lignina foi observada no híbrido 65E3, que diferiu $(\mathrm{P}<0,05)$ dos híbridos MASSA-03, AG-2005 e 699005, enquanto a menor concentração de lignina foi observada no híbrido 699005 , que diferiu $(\mathrm{P}<0,05)$ dos híbridos 65E3, $698007 \mathrm{e}$ 698005.

Os teores de N-FDN/NT, e N-FDA/NT nas plantas não diferiram entre os híbridos, que, segundo Van Soest (1994), são considerados altos, e aponta, como uma das explicações para este fato, a precipi- tação do tanino como proteína complexada durante os procedimentos para a determinação destas frações.

Os componentes químicos do colmo (Tabela 4) que apresentaram diferença entre os híbridos foram os teores de matéria mineral, FDN, FDA, celulose, lignina e N-FDA/NT. Os teores de MS, PB, hemicelulose e N-FDN/NT não diferiram na fração colmo entre os materiais avaliados.

A maior porcentagem dos constituintes da parede celular foi encontrada no colmo do híbrido 65E3. As menores frações de FDN, FDA e celulose foram observadas no híbrido 498111, diferindo $(\mathrm{P}<0,05)$ dos híbridos 65E3 e 698005. Este fato proporcionou menores teores destes constituintes químicos na planta inteira deste híbrido, mesmo tendo alta participação de colmo na planta. O menor conteúdo de lignina foi determinado no colmo do híbrido 699005, diferindo $(\mathrm{P}<0,05)$ dos híbridos 65E3 e 698005.

Para a fração N-FDA/NT a maior complexação do nitrogênio foi observada no híbrido 65E3, superior $(\mathrm{P}<0,05)$ a 498111, 699005 e MASSA-03. Os teores de matéria mineral no colmo foram maiores no híbrido 698007, diferindo apenas do híbrido 498111.

No componente folha (Tabela 5) os teores de matéria seca variaram de 47,57 a $37,42 \%$ para os híbridos 698005 e AG-2005, respectivamente. Trabalhos conduzidos por Neumann et al. (2002b) mostraram teores de MS nas folhas dos híbridos de sorgo variando de 25,9 a $35,2 \%$, quando cultivados na safra

Tabela 4 - Composição bromatológica e constituintes da parede celular do colmo de híbridos de sorgo

Table 4 - Bromatologic composition and cell wall constituents of the steam of sorghum hybrids

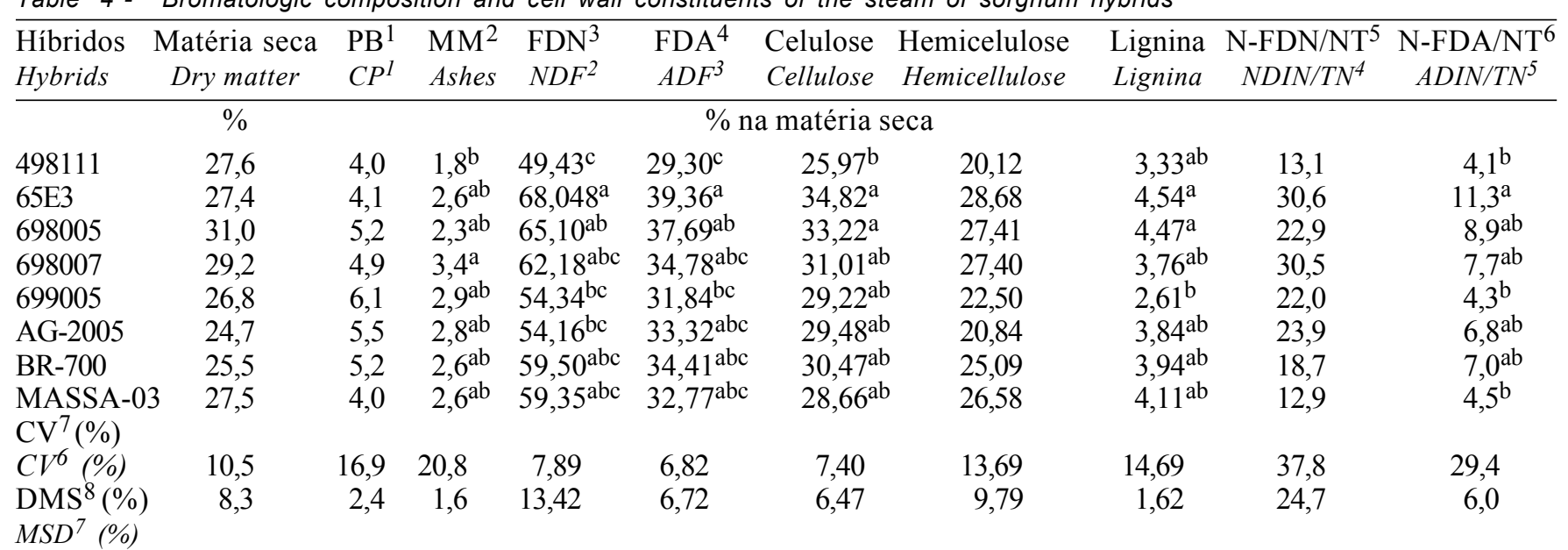

Médias seguidas por letras diferentes na coluna diferem $(P<0,05)$ pelo teste Tukey.

${ }^{1}$ Proteína bruta, ${ }^{2}$ matéria mineral, ${ }^{3}$ fibra em detergente neutro, ${ }^{4}$ fibra em detergente ácido, ${ }^{5}$ nitrogênio insolúvel em detergente neutro em relação ao nitrogênio total, ${ }^{6}$ nitrogênio insolúvel em detergente ácido em relação ao nitrogênio total, ${ }^{7}$ coeficientes de variação, 8 diferenças mínimas significativas.

Means followed by different letters, within a column, differ $(P<.05)$ by Tukey test.

${ }^{1}$ Crude protein, ${ }^{2}$ neutral detergent fiber, ${ }^{3}$ acid detergent fiber, ${ }^{4}$ neutral detergent insoluble nitrogen by total nitrogen, ${ }^{5}$ acid detergent insoluble nitrogen by total nitrogen, ${ }^{6}$ coefficients of variation, ${ }^{7}$ minimun significant differences. 
de novembro a fevereiro, menores que os resultados obtidos neste trabalho $(24,7$ a $31,0 \%)$.

Os maiores teores de lignina estiveram presentes nas folhas do AG-2005 e os menores, no MASSA-03. Para os teores de N-FDN/NT e N-FDA/NT não foram observadas diferenças entre os híbridos, bem como para os teores de PB, MM, FDN, FDA, celulose e hemicelulose. $\mathrm{O}$ fato de as folhas apresentarem altos teores de MS e de parede celular é atribuído a um baixo suprimento de água no decorrer do período experimental (Tabela 1).

Para os constituintes químicos da panícula (Tabela 6), as diferenças $(\mathrm{P}<0,05)$ foram apenas para os teores de MS, lignina, e N-FDA/NT. Com relação aos teores de matéria seca, os dados estiveram dentro dos valores médios observados em outros experimentos. Neumann et al. (2002b), avaliando híbridos de sorgo, encontraram teores de MS na panícula variando de 45,7 a $55,7 \%$, quando essas se encontravam no estádio de grão pastoso a farináceo.

Os teores de matéria seca da panícula e sua participação na planta estiveram relacionados com os teores de matéria seca do híbrido no momento do corte. Altos teores de MS da panícula do híbrido MASSA-03, juntamente com sua participação na planta $(38,5 \%)$, uma das maiores, resultou em altos teores de MS na planta inteira $(37,4 \%)$. Quanto aos teores de proteína bruta, os mesmos estes estiveram abaixo dos resultados obtidos por Chaves
(1997), que avaliando híbridos de sorgo, encontrou valores na fração panícula variando de 7,4 a 9,8\%. Entretanto, Neumann et al. (2002b) apresentaram dados de PB variando de 6,8 a $7,0 \%$ para a mesma fração, próximos aos resultados obtidos neste experimento.

Os teores de FDN e de FDA das panículas estiveram acima dos resultados obtidos por outros autores. Chaves (1997) apresentou valores de FDN e FDA em panículas de sorgo variando de 31,2 a 49,3 e 17,1 a $24,3 \%$, respectivamente. Esse fato observado no presente estudo pode estar relacionado ao déficit hídrico ocorrido no momento de enchimento dos grãos (Tabela 2).

Para estas variáveis, FDN e FDA, não foram observadas diferenças entre os híbridos, o mesmo acontecendo para os teores de celulose e hemicelulose.

No híbrido AG-2005 os valores de lignina estiveram próximos da média encontrada por outros autores (Neumann et al., 2002b) que foi de 3,63\%. A maior porcentagem de lignina foi encontrada na panícula do híbrido BR-700, diferindo $(\mathrm{P}<0,05)$ apenas do híbrido MASSA-3.

Os teores de N-FDN foram considerados altos e podem ser explicados pela possível complexação do tanino dos grãos com a proteína, ocorrendo contaminação da FDN e N-FDN durante as análises químicas (Van Soest, 1994).

A maior complexação do nitrogênio com a FDA

Tabela 5 - Composição bromatológica e constituintes da parede celular das folhas de híbridos de sorgo Table 5 - Bromatologic composition and cell wall constituents of the leaves of sorghum hybrids

\begin{tabular}{|c|c|c|c|c|c|c|c|c|c|c|}
\hline $\begin{array}{l}\text { Híbridos } \\
\text { Hybrids }\end{array}$ & $\begin{array}{l}\text { Matéria seca } \\
\text { Dry matter }\end{array}$ & $\begin{array}{l}\mathrm{PB}^{1} \\
C P^{1}\end{array}$ & $\begin{array}{l}\mathrm{MM}^{2} \\
\text { Ashes }\end{array}$ & $\begin{array}{l}\mathrm{FDN}^{3} \\
N D F^{2}\end{array}$ & $\begin{array}{l}\mathrm{FDA}^{4} \\
A D F^{3}\end{array}$ & $\begin{array}{l}\text { Celulose } \\
\text { Cellulose }\end{array}$ & $\begin{array}{l}\text { Hemicelulose } \\
\text { Hemicellulose }\end{array}$ & $\begin{array}{l}\text { Lignina } \\
\text { Lignina }\end{array}$ & $\begin{array}{c}\text { N-FDN/NT } \\
\text { NDIN/TN }\end{array}$ & $\begin{array}{c}\text { N-FDA/NT } \\
A D I N / T N^{5}\end{array}$ \\
\hline \multicolumn{9}{|c|}{$\%$ na matéria seca } & & \\
\hline 498111 & $42,4^{\mathrm{abc}}$ & 4,8 & 4,0 & 76,81 & 40,35 & 35,08 & 36,47 & $5,27^{\mathrm{ab}}$ & 53,4 & 18,2 \\
\hline $65 \mathrm{E} 3$ & $41,9^{\mathrm{abc}}$ & 5,0 & 3,7 & 73,04 & 41,68 & 36,92 & 31,36 & $4,76^{\mathrm{ab}}$ & 47,5 & 19,0 \\
\hline 698005 & $47,5^{\mathrm{a}}$ & 4,5 & 4,5 & 67,61 & 37,70 & 33,36 & 29,90 & $4,35^{\mathrm{ab}}$ & 50,6 & 16,8 \\
\hline 698007 & $45,4^{\mathrm{ab}}$ & 5,1 & 4,9 & 70,15 & 37,92 & 32,86 & 32,23 & $5,06^{\mathrm{ab}}$ & 38,5 & 22,1 \\
\hline 699005 & $43,3^{a b c}$ & 5,9 & 4,3 & 72,51 & 41,12 & 36,78 & 31,38 & $4,34^{\mathrm{ab}}$ & 48,6 & 14,7 \\
\hline AG-2005 & $37,4^{\mathrm{c}}$ & 5,3 & 4,2 & 72,30 & 41,89 & 36,16 & 30,41 & $5,73^{\mathrm{a}}$ & 48,4 & 21,6 \\
\hline BR-700 & $38,8^{b c}$ & 6,6 & 4,5 & 72,40 & 42,14 & 37,23 & 30,26 & $4,91^{\mathrm{ab}}$ & 46,5 & 15,4 \\
\hline MASSA-03 & $39,7^{b c}$ & 5,3 & 4,3 & 68,98 & 37,72 & 34,33 & 31,26 & $3,39^{\mathrm{b}}$ & 49,5 & 15,0 \\
\hline $\mathrm{CV}^{7}(\%)$ & 5,5 & 14,7 & 11,8 & 4,58 & 5,76 & 5,93 & 10,90 & 14,06 & 23,0 & 35,5 \\
\hline$C V^{6}(\%)$ & & & & & & & & & & \\
\hline $\mathrm{DMS}^{8}(\%)$ & 6,7 & 2,2 & 1,4 & 9,47 & 6,64 & 6,03 & 9,94 & 1,91 & 31,8 & 18,3 \\
\hline$M S D^{7}(\%)$ & & & & & & & & & & \\
\hline
\end{tabular}

Médias seguidas por letras diferentes na coluna diferem $(P<0,05)$ pelo teste Tukey.

${ }^{1}$ Proteína bruta, ${ }^{2}$ matéria mineral, ${ }^{3}$ fibra em detergente neutro, ${ }^{4}$ fibra em detergente ácido, ${ }^{5}$ nitrogênio insolúvel em detergente neutro em relação ao nitrogênio total, ${ }^{6}$ nitrogênio insolúvel em detergente ácido em relação ao nitrogênio total, ${ }^{7}$ coeficientes de variação, 8 diferenças mínimas significativas.

Means followed by different letters, within a column, differ $(P<.05)$ by Tukey test.

${ }^{1}$ Crude protein, ${ }^{2}$ neutral detergent fiber, ${ }^{3}$ acid detergent fiber, ${ }^{4}$ neutral detergent insoluble nitrogen by total nitrogen, ${ }^{5}$ acid detergent insoluble nitrogen by total nitrogen, ${ }^{6}$ coefficients of variation, ${ }^{7}$ minimun significant differences.

R. Bras. Zootec., v.32, n.5, p.1083-1092, 2003 
Tabela 6 - Composição bromatológica e constituintes da parede celular das panículas de híbridos de sorgo Table 6 - Bromatologic composition and cell wall constituents of the panicles of sorghum hybrids

\begin{tabular}{|c|c|c|c|c|c|c|c|c|c|c|}
\hline $\begin{array}{l}\text { Híbridos } \\
\text { Hybrids }\end{array}$ & $\begin{array}{l}\text { Matéria seca } \\
\text { Dry matter }\end{array}$ & $\begin{array}{l}\mathrm{PB}^{1} \\
C P^{1}\end{array}$ & $\begin{array}{l}\mathrm{MM}^{2} \\
\text { Ashes }\end{array}$ & $\begin{array}{l}\mathrm{FDN}^{3} \\
N D F^{2}\end{array}$ & $\begin{array}{l}\mathrm{FDA}^{4} \\
A D F^{3}\end{array}$ & $\begin{array}{l}\text { Celulose } \\
\text { Cellulose }\end{array}$ & $\begin{array}{l}\text { Hemicelulose } \\
\text { Hemicellulose }\end{array}$ & $\begin{array}{l}\text { Lignina } \\
\text { Lignina }\end{array}$ & $\begin{array}{c}\text { N-FDN/NT } \\
N D I N / T N^{4}\end{array}$ & $\begin{array}{c}\text { N-FDA/NT } \\
A D I N / T N^{5}\end{array}$ \\
\hline \multicolumn{9}{|c|}{$\%$ na matéria seca } & & \\
\hline 498111 & $59,2^{\mathrm{ab}}$ & 7,1 & 4,0 & 54,0 & 25,5 & 20,2 & 28,5 & $5,3^{\mathrm{ab}}$ & 46,1 & $17,6^{\mathrm{bc}}$ \\
\hline $65 \mathrm{E} 3$ & $56,7^{\mathrm{ab}}$ & 7,6 & 3,0 & 52,7 & 27,9 & 23,3 & 24,8 & $4,5^{\mathrm{ab}}$ & 49,4 & $25,6^{\mathrm{b}}$ \\
\hline 698005 & $60,5^{\mathrm{ab}}$ & 6,8 & 4,0 & 55,5 & 27,6 & 22,6 & 27,9 & $5,0^{\mathrm{ab}}$ & 48,4 & $17,8^{\mathrm{bc}}$ \\
\hline 698007 & $61,2^{\mathrm{a}}$ & 7,0 & 4,1 & 55,0 & 30,6 & 25,7 & 24,4 & $4,9^{\mathrm{ab}}$ & 40,6 & $20,2^{b c}$ \\
\hline 699005 & $53,3^{\mathrm{ab}}$ & 7,1 & 3,3 & 51,2 & 27,7 & 22,6 & 23,5 & $5,1^{\mathrm{ab}}$ & 35,5 & $16,4^{\mathrm{c}}$ \\
\hline AG-2005 & $49,8^{\mathrm{b}}$ & 7,1 & 3,8 & 54,3 & 27,4 & 22,7 & 26,8 & $4,7^{\mathrm{ab}}$ & 39,9 & $19,6^{\mathrm{bc}}$ \\
\hline BR-700 & $51,7^{\mathrm{ab}}$ & 7,8 & 3,4 & 50,8 & 28,3 & 22,0 & 22,4 & $6,3^{a}$ & 50,5 & $37,5^{a}$ \\
\hline MASSA-03 & $61,0^{\mathrm{a}}$ & 6,5 & 3,6 & 46,8 & 23,3 & 20,0 & 23,4 & $3,3^{b}$ & 51,8 & $17,0^{\mathrm{bc}}$ \\
\hline $\mathrm{CV}^{7}(\%)$ & 6,6 & 11,0 & 19,6 & 7,6 & 10,7 & 14,2 & 11,9 & 17,9 & 16,5 & 14,6 \\
\hline$C V^{6}(\%)$ & & & & & & & & & & \\
\hline $\begin{array}{l}\operatorname{DMS}^{8}(\%) \\
M S D^{7}(\%)\end{array}$ & 10,8 & 2,2 & 1,5 & 11,5 & 8,4 & 9,2 & 8,7 & 2,5 & 21,6 & 9,0 \\
\hline
\end{tabular}

Médias seguidas por letras diferentes na coluna diferem $(P<0,05)$ pelo teste Tukey.

${ }^{1}$ Proteína bruta, ${ }^{2}$ matéria mineral, ${ }^{3}$ fibra em detergente neutro, ${ }^{4}$ fibra em detergente ácido, ${ }^{5}$ nitrogênio insolúvel em detergente neutro em relação ao nitrogênio total, ${ }^{6}$ nitrogênio insolúvel em detergente ácido em relação ao nitrogênio total, ${ }^{7}$ coeficientes de variação, 8 diferenças mínimas significativas.

Means followed by different letters, within a column, differ $(P<.05)$ by Tukey test.

${ }^{1}$ Crude protein, ${ }^{2}$ neutral detergent fiber, ${ }^{3}$ acid detergent fiber, ${ }^{4}$ neutral detergent insoluble nitrogen by total nitrogen, ${ }^{5}$ acid detergent insoluble nitrogen by total nitrogen, ${ }^{6}$ coefficients of variation, ${ }^{7}$ minimun significant differences.

ocorreu na panícula do híbrido BR-700 e a menor, no híbrido 699005, que por sua vez não apresentou diferenças dos híbridos MASSA-03, 498111, 698007, AG-2005 e 698005.

\section{Análise de Agrupamento}

O resultado da análise de agrupamento foi apresentado na forma de dendrograma (Figura 1) considerando a altura Euclideana para formação de conglomerados.

Pela avaliação da Figura 1, pode-se verificar que a formação dos agrupamentos iniciou-se relativamente em baixas distâncias de ligações, evidenciando similaridade na resposta para alguns dos genótipos.

Optou-se por utilizar como ponto de parada para definição dos agrupamentos a distância de ligação 1,6 , tentando-se não levar a uma fragmentação excessiva dos agrupamentos, que já aconteceria na distância de ligação 0,8 . Por outro lado a utilização de uma distância de ligação muito alta levaria a formação de grupos com pouca discriminação dos híbridos. Com isso, foram definidos quatro conglomerados principais, que pode ser verificado na Figura 1 e na Tabela 7.

Correlacionando este agrupamento com os dados médios das variáveis utilizadas (Tabela 7), pode-se propor, como principais interpretações, a existência de um grupo de híbridos com menor produção de matéria seca, representados pelos primeiro e segundo conglomerados, que ao mesmo tempo apresentam alta participação de panícula na planta inteira, sendo que o híbrido BR 700, de forma isolada, forma o primeiro conglomerado, devido ao menor valor de NDT e também maior porcentagem de $\mathrm{PB}$ em relação às
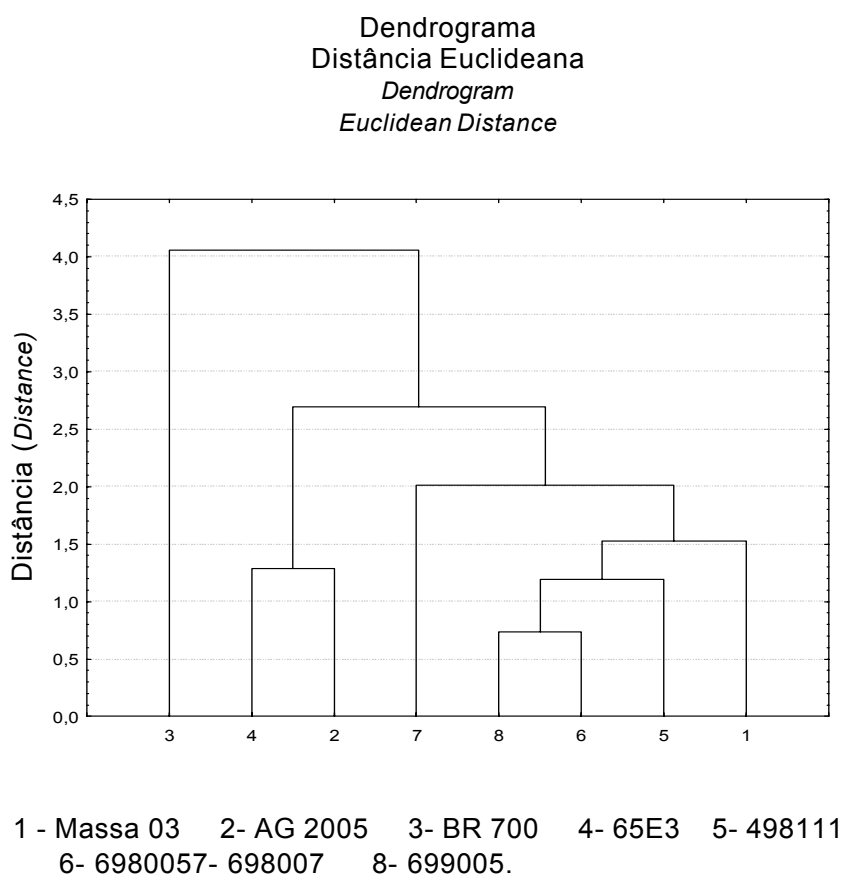

Figura 1 - Dendrograma da análise de Cluster realizada para agrupamento dos híbridos de sorgo.

Figure 1 - Dendrogram of Cluster Analyses for grouping hybrids of sorghum. 
Tabela 7 - Perfil dos grupos de híbridos de sorgo formados pela análise de agrupamento de parâmetros ligado a produção de matéria seca (PMS), porcentagem de panícula (PAN), nutrientes digestíveis totais (NDT) e proteína bruta $(\mathrm{PB})$, referente a média dos constituintes de cada grupo

Table 7 - Sorghum hybrids distribution, according a group analyses, considering dry matter production (DMP), panicle content (\%), total digestible nutrients (TDN), and crude protein (\%), considering an average of the constituents in each group

\begin{tabular}{|c|c|c|c|c|c|}
\hline $\begin{array}{l}\text { Grupos } \\
\text { Groups }\end{array}$ & $\begin{array}{l}\text { Híbridos } \\
\text { Hybrids }\end{array}$ & $\begin{array}{l}\operatorname{PMS}(\mathrm{t} / \mathrm{ha}) \\
D M P(t / h a)\end{array}$ & $\begin{array}{l}\text { PAN (\%) } \\
\text { PAN (\%) }\end{array}$ & $\begin{array}{l}\text { NDT (\%) } \\
T D N(\%)\end{array}$ & $\begin{array}{l}\text { PB (\%) } \\
C P(\%)\end{array}$ \\
\hline 1 & BR-700 & 5,09 & 42,19 & 63,07 & 8,82 \\
\hline 2 & $\begin{array}{c}\text { 65E3 } \\
\text { AG-2005 }\end{array}$ & 5,74 & 44,98 & 68,31 & 7,37 \\
\hline 3 & 698007 & 7,06 & 35,92 & 64,04 & 7,12 \\
\hline 4 & $\begin{array}{c}699005 \\
698005 \\
498111 \\
\text { MASSA-03 }\end{array}$ & 6,50 & 32,76 & 67,08 & 6,94 \\
\hline
\end{tabular}

Método das distancias médias (MMD) e dissimilaridade baseada na distância Euclideana de variáveis padronizadas. Average distances methods (ADM), and dissimilarity, considering Euclidean distance of the standard variables.

demais médias. Já os híbridos 65E3 e o AG 2005 (grupo 2) foram agrupados em função aditiva das maiores concentrações estimadas de NDT nas plantas.

Por outro lado, pode-se observar o quarto grupo formado pelos híbridos 699005, 698005, $498111 \mathrm{e}$ Massa 03 com PMS maior que os híbridos do primeiro e segundo grupo, e ainda o terceiro grupo formado pelo híbrido 698007, com a maior PMS. Entretanto, os híbridos do terceiro e quarto conglomerados apresentaram menor porcentagem de panícula em relação às demais médias e ainda com teores de NDT menores que os híbridos que compõem o segundo grupo.

\section{Conclusões}

De forma geral, todos os híbridos apresentaram teores de matéria seca e carboidratos solúveis adequados ao processo de ensilagem, no entanto, o melhor equilíbrio entre as partes constituintes, colmo, folhas e panícula, bem como a melhor composição química das plantas, considerando o aspecto nutricional, foi observada nos híbridos AG-2005 e 65E3. A análise de agrupamento também sugeriu a existência de similaridade para estes dois genótipos que, apesar de apresentarem menores produções de matéria seca, atenderam melhor aos aspectos morfológicos e nutricionais.

\section{Literatura Citada}

BUSSAB, W.O.; MIAZAKI, E.S.; ANDRADE, D.F. Introdução à análise de agrupamento. In: SIMPÓSIO NACIONAL DE PROBABILIDADE E ESTATÍSTICA, 9., 1990, São Paulo. Anais ... São Paulo: ABE, 1990. 105p.

CHAVES, A.V. Avaliação de cultivares de sorgo (Sorghum bicolor L. Moench) para produção de silagem. Viçosa, MG: Universidade Federal de Viçosa, 1997. 35p. Dissertação (Mestrado em Fitotecnia) - Universidade Federal de Viçosa, 1997.

DEMARCHI, J.J.A.A.; BOIN, C.; BRAUN, G. A cultura do sorgo (Sorghum bicolor L. Moench) para produção de silagem de alta qualidade. Zootecnia, v.33, n.3, p.111-136, 1995.

ETHERIDGE, R.D.; PESTI, G.M.; FOSTER, E.H. A comparison of nitrogen values obtained utilizing the Kjeldahl nitrogen and Dumas combustion methodologies (Leco CNS 2000) on samples typical of an animal nutrition analytical laboratory. Animal Feed Science and Thecnology, v.73, n.1, p.21-28, 1998.

FLARESSO, J.A.; GROSS, C.D.; ALMEIDA, E.X. Cultivares de milho (Zea mays L.) e sorgo (Sorghum bicolor (L.) Moench) para ensilagem no Alto Vale do Itajaí, Santa Catarina. Revista Brasileira de Zootecnia, v.29, n.6, p.1608-1615, 2000.

GORDON, C.H. Storage losses in silage as affected by moisture content and structure. Journal of Dairy Science, v. 50, n.3, p.397-403, 1967.

GOURLEY, L.M.; LUSK, J.W. Sorghum silage quality as affected by soluble carbohydrate, tannins and other factors. In: ANNUAL CORN AND SORGHUM RESEARCH CONFERENCE, 32, 1977, Mississipi. Proceedings... Mississipi: Mississipi State University, 1977. p.157-170. HENRIQUE, W.; ANDRADE, J.B. Silagem de milho, sorgo, 
girassol e suas consorciações. I. Produção e composição. In: REUNIÃO ANUAL DA SOCIEDADE BRASILEIRA DE ZOOTECNIA, 34., 1997, Juiz de Fora. Anais... Juiz de Fora: SBZ/Geratec, [1997] CD-ROM. Nutrição de ruminantes. BNRU-343.

JOHNSON, R.R.; BALWANI, T.L.; JOHNSON, L.J. et al. Corn plant maturity. II. Effect on "in vitro" cellulose digestibility and soluble carbohydrate content. Journal of Animal Science, v.25, n.3, p.617-623, 1966.

JOHNSON, R.R.; FARIA, V.P.; McCLURE, R.E. Effects of maturity on chemical composition and digestibility of bird resistant sorhgum plants wen fed to sheeps on silages. Journal of Animal Science, v. 33, n.5, p.1102-1109, 1971.

KEPLIN, L.A.S. Recomendação de sorgo e milho (silagem) safra 1992/93. Revista Batavo, v.1, n.8, p.16-19.

McDONAld, P.; HENDERSON, A.R.; HERSON, S. The biochemistry of silage. 2.ed. Marlow: Chalcombe, 1991. $340 \mathrm{p}$.

MINSON, D.J. Forage in ruminant nutrition. New York: Academic Press, 1990. 483p.

NATIONAL RESEARCH COUNCIL - NRC. Nutrient requirements of dairy cattle. Washington, D.C.: National Academy Press, 2001. 381p.

NELSON, C.J.; MOSER, L.E. Plant factors affecting forage quality. In: FAHEY Jr., G.C. (Ed). Forage quality, evaluation and utilization. Madison: American Society of. Agronomy, 1994. p.115-154.

NEUMANN, M.; RESTLE, J.; ALVES FILHO, D.C. et al. Avaliação do valor nutritivo da planta e da silagem de diferentes híbridos de sogo (Sorghum bicolor, L. Moench). Revista Brasileira de Zootecnia, v.31, n.1, p.293-301, 2002a.

NEUMANN, M.; RESTLE, J.; ALVES FILHO, D.C. et al. Avaliação de diferentes híbridos de sogo (Sorghum bicolor, L. Moench) quanto aos componentes da planta e silagens produzidas. Revista Brasileira de Zootecnia, v.31, n.1, p.302-312, 2002b.

NUSSIO, L.G. Milho e sorgo para produção de silagem. In: PEIXOTO, A.M.; MOURA, J.C.; FARIA, V.P. (Ed.) Volumosos para bovinos. Piracicaba: Fundação de Estudos Agrários "Luiz de Queiroz", 1993. p.75-177.

OWEN, F.G. Factors affecting nutritive value of corn and sorghum silage. Journal of Dairy Science, v.50, n.3, p.404-416, 1967.

PEREIRA, O.G. Produtividade do milho (Zea mays L.), do sorgo (Sorghum bicolor (L.) Moench), da aveia (Avena sativa), do milheto (Pennisetum americanum $\mathrm{L}$.) e do híbrido ( $S$. bicolor $x$ S. sudanense), e respectivos valores nutritivos sob a forma de silagem e verde picado. Viçosa, MG: Universidade Federal de Viçosa, 1991. 86p. Dissertação (Mestrado em Zootecnia) - Universidade Federal de Viçosa, 1991.
PESCE, D.M.C.; GONÇALVES, L.C.; RODRIGUES, J.A.S. et al. Análise de vinte genótipos de sorgo (Sorghum bicolor (L.) Moench) de porte médio e alto, pertencentes ao ensaio nacional. Revista Brasileira de Zootecnia, v.29, n.4, p.978-987, 2000.

PIMENTEL, C.R.M.; LIRA, M.A.; FARIAS, M.A. et al. Época de plantio para sorgo e milho nos Estados de Pernambuco e Paraíba: Estudos preliminares baseados em probabilidade de chuva. Pesquisa Agropecuária Pernambucana, v.1, n.1, p.127-142, 1977.

SILVA, D.J. Análise de alimentos: métodos químicos e biológicos. 2.ed. Viçosa, MG: Universidade Federal de Viçosa, 1998. 166p.

SILVA, F.F.; GONÇALVES, L.C.; RODRIGUES, J.A.S. et al. Qualidade de silagens de híbridos de sorgo (Sorghum bicolor (L.) Moench) de portes baixo, médio e alto com diferentes proporções de colmo+folha/panícula 1 . Avaliação do processo fermentativo. Revista Brasileira de Zootecnia, v.28, n.1, p.14-20, 1999.

STATISTICAL ANALYSIS SYSTEMS. User's guide: statistics. version 6. Cary: 1990.

VALENTE, J.O. Manejo cultural do sorgo para forragem. 2.ed. Sete Lagoas: EMBRAPA-CNPMS, 1997. p.5-7. (Circular Técnico, 17)

Van SOEST, P.J. Nutritional ecology of the ruminant. 2.ed. Ithaca: Cornell University Press, 1994. 476p.

Van SOEST, J.P.; ROBERTSON, J.B.; LEWIS, B.A. Methods for dietary fiber, neutral detergent fiber, and nonstarch polysaccharides in relation to animal nutrition. Journal of Dairy Science, v.74, n.10, p.3583-3597, 1991.

ZAGO, C.P. Cultura de sorgo para produção de silagem de alto valor nutritivo. In: SIMPÓSIO SOBRE NUTRIÇÃO DE BOVINOS, 4, 1991, Piracicaba. Anais... Piracicaba: Fundação de Estudos Agrários "Luiz de Queiroz", 1991.p.169-217.

ZAGO, C.P. Silagem de sorgo. In: SIMPÓSIO SOBRE NUTRIÇÃO DE BOVINOS, 7, 1999, Piracicaba. Anais... Piracicaba: Fundação de Estudos Agrários "Luiz de Queiroz", 1999. p.47-68. 